\title{
Optimized Operation of PV/T and Micro-CHP Hybrid Power Systems
}

\author{
Abdalkarim Awad $^{1} \cdot$ Peter Bazan $^{1} \cdot$ Reinhard German $^{1}$
}

Received: 3 November 2014 / Accepted: 4 January 2016 / Published online: 23 January 2016

(c) Springer Science+Business Media Singapore 2016

\begin{abstract}
Specialists generally agree that Distributed Energy Resources $(D E R s)$ will play a key role in the next generation power systems. Photovoltaic (PV) solar panels are very important energy conversion methods, yet they suffer from low energy conversion efficiency, availability issues and fluctuating output. Photovoltaic/Thermal (PV/T) has been introduced as a way to increase the efficiency of the system by utilizing the co-generated heat. Combining PV/T with Combined Heat and Power $(C H P)$ units is considered as a promising approach to encounter the intermittent and availability issues of solar energy. Smart grids, on the other hand, create opportunities for intelligent coordination between the different elements in the power grid. In this technologically focused paper we study the optimal operational strategies of coupled DERs and storage within different scenarios. At the beginning we show the optimal sizes of different components, taking into consideration loads and investment costs. We introduce an approach to optimize the usage of the battery in which a controller tries to hold the battery near the optimal level and avoids unnecessary discharge operations. Furthermore, we explore the usage of feed-forward artificial neural networks to
\end{abstract}

Abdalkarim Awad

abdalkarim.awad@cs.fau.de

Peter Bazan

peter.bazan@cs.fau.de

Reinhard German

german@cs.fau.de

1 Computer Networks and Communication Systems, Department of Computer Science, University of Erlangen, Martensstr 3, 91058 Erlangen, Germany estimate the demand. Starting with simple setups (i.e., only $\mathrm{PV}$ and Battery) and going then to more complex setups (i.e., with $\mu C H P$ ), we have shown through comprehensive simulation studies that it is possible to enhance the profit when the optimized approach is applied.

Keywords Distributed Energy Resources - Photovoltaics · $\mu C H P \cdot$ Optimization $\cdot$ Smart grid

\section{Introduction}

$D E R s$ such as photovoltaic $(P V)$ panels, micro turbines and windmills provide technologically feasible solutions to the current environmental challenges created by the current dominance of fossil fuel-based electrical power generation [29]. Nevertheless, these types of sources suffer from two main problems. Firstly they have usually low efficiency and secondly, most of them, especially $P V$ and windmills, suffer from a high rate of uncertainty and therefore they are difficult to control. Additionally, some of them are not available all over the time, e.g., solar energy is not available in the night. To encounter the first problem, the concept of cogeneration of power is applied. Because $\mu C H P$ generates electricity and heat simultaneously, it is an efficient way to supply energy.

The $P V / T$ concept provides an opportunity to increase overall efficiency of $P V$ panels by making use of waste heat generated in the PV module. Because increasing the temperature will decrease the voltage, the efficiency of a PV solar cell decreases with the increase in the operating temperature and hence cooling is beneficial. PV cooling may be achieved by circulating a colder substance, water or air, at its rear or front surface or both surfaces. In $P V / T$ systems, solar thermal collectors are combined with PV cells to form 
hybrid energy-generating units that simultaneously supply the two types of energy required by most consumers, heat and electricity. Combining controllable DERs with renewable energy sources tackles the second problem such that it reduces the effect of fluctuation and availability issues. Furthermore, adding energy storage units will also reduce the effect of uncertainty of renewable energy sources and enhance their sustainability. The work in [29] showed that combining PV and $\mu$ C H P not only has the potential to radically reduce energy waste in the status of electrical and heating systems, but it also enables the share of PV to be expanded significantly.

According to the United States Federal Energy Regulatory Commission, demand response is a tariff or program established to motivate changes in electricity use by end-use customers in response to changes in the price of electricity over time, or to give incentive payments designed to induce lower electricity use at times of high market prices or when grid reliability is jeopardized [31]. Nevertheless, in the literature other definitions can be found. The focus of this paper is on price-based demand response which can be employed to reduce power demand on high demand periods by introducing a variable price during the day [28]. The basic idea is to introduce a high price in the high residual demand periods and a lower price in the low residual demand periods. This approach encourages end users to shift some of the demand from high demand periods to low demand periods. Depending on internal and external conditions such as demand, weather, and price, they can decide to buy, store or sell electricity with various strategies in order to come close to self-sufficiency or in order to decrease costs or even achieve profit. The more households will be enabled with such possibilities, the more this will have an impact on the business model of utility companies. In order to investigate such effects, a combined simulation and optimization model of a network of such houses connected to a utility company is presented in this paper.

Because PV has a higher feed-in tariff than $\mu C H P$, a simple strategy for houses equipped with photovoltaics and $\mu C H P$ is to just feed all electricity into the grid which is generated by the solar modules, to use the electricity produced by $\mu C H P$ to cover local demand, and to buy needed electricity from the utility company which can't be covered by $\mu C H P$. This is an attractive option if the feed-in tariff for the electricity produced by the $P V$ is high and the price to buy electricity is low enough. However, feed-in-tariffs get lower and electricity prices get higher. Prices for batteries are getting lower, and hence, using them eventually becomes an attractive option. Another simple operation strategy is to try to achieve self-sufficiency: the demand is first tried to be satisfied from the solar module and $\mu C H P$, then by the battery, and at last option by the grid. Excess charges first the battery and if this is not possible is fed into the grid. A potential drawback of this self-sufficiency strategy is that it is probably not optimal, neither from the economical perspective of the single house, nor from the perspective of the national economics. Furthermore, the self-sufficiency strategy does not take the possibility of shifting loads into account.

Motivated by the decreasing costs of $D E R s$ and energy storage technologies, the increasing costs of electricity for households, and the decreasing benefits of feed-in tariff, new strategies for power management inside a house are required. In this technologically concentrated work we utilize linear programming to find the optimal operating parameters to increase the household revenue. We start the investigation of the optimal coordination with a simple setup in which we consider only PV systems with batteries. Then we study the coupled operation of privately owned $\mu \mathrm{CH} P$ and $P V / T$ systems. We consider houses that are participants in the smart grid and hence, information such as electricity day-ahead prices and demand forecasts are available. The proposed electrical and heat power management controller exploits day-ahead prices, demand on electricity and heat forecasts as well as weather forecasts to enhance the profit of the whole system. We have run experiments without uncertainty in the demand and supply forecast and then we explored the effect on forecast uncertainty by utilizing an artificial neural network approach to predict demand on electricity. The main contributions can be summarized as follows:

- We present an extended version of our previous work [4-6] that optimizes the profit from a hybrid energy system that has heat demand, $P V / T$, and $\mu C H P$ which were only partially investigated in our previous work.

- We introduced a method to optimize the overall usage of the battery that takes into consideration not only the state of charge (SOC) but also the effect of charging/discharging cycles.

- Taking electricity and heat demand and investment costs as inputs, we show the optimal size of each component.

- In a comprehensive simulation study, we studied the savings when applying the optimized approach compared to a self-sufficiency based approach. We explored savings under different scenarios such as PV panel size, battery size, amount of elastic load and remuneration method.

- We explored the effect of uncertainty in forecasted information and we provided a neural network base demand estimator.

- We explored also the capability of the approach under system limitations such as battery size and elastic load requirements. 
The rest of the paper is organized as follows. In Section Related Work we provide a summary about related works. In Section The Optimization Problem we present our approach and in Section Evaluation we evaluate the performance of the proposed scheme. Finally, Section Discussion and Conclusions concludes the paper.

\section{Related Work}

In [29] the author investigates the potential of deploying a distributed network of PV and CHP hybrid systems in order to increase the PV penetration level in the U.S. The temporal distribution of solar flux, electrical and heating requirements for representative U.S. single family residences were analyzed and the results show that hybridizing CHP with PV can enable additional PV deployment above what is possible with a conventional centralized electric generation system. The technical evolution of such PV+CHP hybrid systems was developed from the near-market technology through several generations, which enable high utilization rates of both PV-generated electricity and CHP-generated heat. The author derived a method to determine the maximum percent of PV-generated electricity on the grid without energy storage. The results show that a PV+CHP hybrid system not only has the potential to radically reduce energy waste in the status quo electrical and heating systems, but it also enables the share of solar PV to be expanded significantly.

The authors in [26] use game theory to formulate an energy consumption scheduling game, where the players are the users and their strategies are the daily schedules of their household appliances and loads. They assumed that the utility company can adopt adequate pricing tariffs that differentiate the energy usage in time and level. They have shown, that for a common scenario, with a single utility company serving multiple customers, the global optimal performance in terms of minimizing the energy costs is achieved at the Nash equilibrium of the formulated energy consumption scheduling game. The study in [30] utilizes smart meter readings to implement smart control of $\mu C H P$, storage, and demand response in microgrids. The work in [12] introduces an analysis framework and a relevant unified and synthetic Mixed-Integer Linear Programming optimization model suitable for evaluating the techno-economic and environmental characteristics of different Distributed MultiGeneration (DMG) options. The authors in [20] proposed a strategy aimed at demand response for more intelligent control of $\mu C H P$ systems. This work is similar to our work in terms of using day-ahead prices to optimize the operation of a house, nevertheless they focus on demand response with respect to heating systems, while our work takes into consideration hybrid systems with $\mathrm{PV}, \mu C H P$ and power storage units. Additionally, our approach considers the costs of battery usage and explores the impact of uncertainty on the savings. The work in [13] presents PV self-consumption as an approach for Active Demand-Side Management for the residential sector. The authors then used neural networks to enhance the use of local generated power [22]. The authors in [14] formulated a linear optimization problem to identify the optimum daily operational strategy for the wind-hydro storage plants. Wind power was assumed as deterministic in [14], while in [27] forecasted wind power was represented as a stochastic variable.

In [19] a mixed-integer linear programming (MILP) model of the energy management structure is provided to investigate a collaborative evaluation of dynamic-pricing and power limiting based demand response strategies. The author has considered Electric Vehicles (EVs) with bi-directional power flow capability and Energy Storage Systems (ESSs). [32] discusses the potential to increase PV self-consumption through scheduling of household appliances in 200 Swedish single-family buildings. The authors in [15] used linear programming to efficiently compute a deterministic scheduling solution without considering uncertainties. To handle the uncertainties in household appliance operation time and energy consumption, a stochastic scheduling technique, which involves an energy consumption adaptation variable, is used to model the stochastic energy consumption patterns for various household appliances.

The impact of adding an electric storage system to a house equipped with a combination of renewable heat and electricity generation is investigated in [17]. For this purpose a linear mathematical program is given and solved by MATLAB for several periods of four days. The objective is to minimize the energy costs for consumed electricity and gas. As deterministic input for renewable energy conversion, energy demand, and wholesale spot prices, measured values are used together with demand profiles. The work in [11] addresses the problem of modelling the uncertainty of the input data, such as solar irradiation or temperature profiles. The linear program for households with PV and battery is solved for one year with the objective to reduce the energy costs. In contrast to our work, a flat electricity tariff is assumed.

To identify the optimum daily operational strategy to be followed by PV systems, a prediction of daily solar power generation is required. The values of insolation (solar irradiation) are the most important parameters for the solar energy applications. Some approaches to forecast solar power generation are focused on numerical weather prediction models [21]. Others are focused on predicting solar radiation from satellite images of cloud movements [25]. Several methods have been proposed to forecast power demand. The survey in [1] discusses some approaches such as multiple regression, exponential smoothing and iterative reweighted 


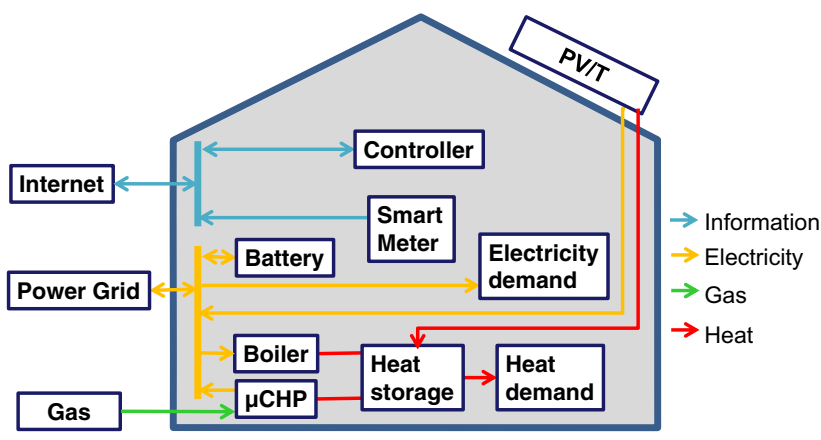

(a)

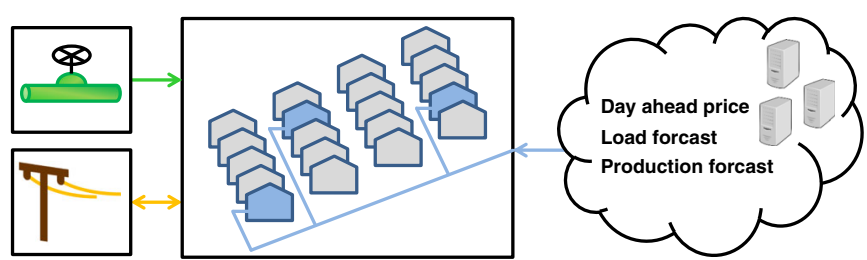

(b)

Fig. 1 House with PV/T, $\mu C H P$ and energy storage units (a), and group of houses as participants of a smart grid (b)

least-squares which can be used to predict power demand. In [33] an ARMAX model for short term load forecasting and in [7] neural networks are used to estimate household electricity consumption.

\section{The Optimization Problem}

We consider a house that privately owns $P V / T$ and $\mu C H P$ systems (Fig. 1a) and is a participant of a smart grid as shown in Fig. 1b. The electricity produced by the $P V / T$ or $\mu C H P$ can be used locally, stored, or exported to the grid. The heat generated by the PV/T or $\mu C H P$ must be stored in the heat storage unit to be used for local heat demand. Additionally, we have assumed that the house contains an electrical unit (auxiliary boiler) that can cover heat demand if the heat generated by the $\mu C H P$ and $P V / T$ is not sufficient. To identify the optimal daily operation strategy to be followed by the energy system, the day-ahead electricity price, a prediction of daily solar power, and a prediction of the energy demands are needed. During the day, a house may be a power consumer or producer - also known as "prosumer". We assume that a prediction of PV energy is available through weather information, e.g., through information about solar insolation. To solve the optimization problem, we assume that the solver either runs locally or is provided as a service through the communication system. Similarly, supply and demand forecasting algorithms can be run locally or provided as a service through the communication network.

The household controller maximizes the corresponding revenue by using the battery (charging/discharging) or by exchanging power with the grid. Households exchange power with the main grid at market price. Additionally, the controller coordinates the work of the $\mu C H P$ such that it provides the maximum profit.
The main idea is to use the day-ahead price, the electricity and heat demand, and the weather forecast to find the optimal strategy to be followed to maximize the profit of a household. The controller uses the day-ahead price, demand forecast, and energy supply forecast to solve an optimization problem to find the optimal amount of energy to be sold, charged/discharged in/from the energy storage unit, and the amount of electricity to be imported from the grid. If the house has elastic loads, then it finds also the optimal time slot to run these loads. The controller solves the optimization problem below for one day, i.e., the optimization time horizon is $T=24$ hours. Then, according to the results, it changes the current operating parameters of the system. This process is repeated periodically for the rest of the day with time step $\delta=1$ hour (i.e., $T=23,22,21, \ldots$ ). Table 1 summarizes the model nomenclature.

The optimization problem can now be defined. The objective function given as:

$\max \sum_{t=0}^{T}\{\operatorname{profit}(t)\}$

We can define the profit at time $t$ as the difference between the earnings at time $t$ and the costs at time $t$.

$\operatorname{profit}(t)=\operatorname{earnings}(t)-\cos t s(t)$

The earnings come from selling $\mathrm{PV}$ and $\mu C H P$ electricity to the grid, while the costs come from importing energy from the network, running the $\mu C H P$, and using the battery.

$$
\begin{array}{r}
\max \sum_{t=0}^{T}\left(C_{f-p v} \delta P_{s-p v}(t)+C_{f-c h p} \delta P_{s-c h p}(t)\right. \\
\left.-C(t) \delta P_{b}(t)-C_{c h p}(t) \delta P_{c h p}(t)-\delta C_{B a t}(t)\right) \\
+C_{\text {heat }} H(T)+C(T) \eta_{d} E(T)
\end{array}
$$


Table 1 Summary of the model nomenclature

\begin{tabular}{|c|c|c|c|}
\hline Component & Paramter & Summery & Unit \\
\hline \multirow{14}{*}{ Battery } & $\eta_{c}$ & Battery charging efficiency & - \\
\hline & $\eta_{d}$ & Battery discharging efficiency & - \\
\hline & $P_{c}(t)$ & Power charged in the battery at time $\mathrm{t}$ & $\mathrm{kW}$ \\
\hline & $P_{d}(t)$ & Power discharged from the battery at time $\mathrm{t}$ & $\mathrm{kW}$ \\
\hline & $P_{c}^{\max }$ & Max charge power & $\mathrm{kW}$ \\
\hline & $P_{d}^{\max }$ & Max discharge power & $\mathrm{kW}$ \\
\hline & $E(t)$ & Battery SOC & $\mathrm{kWh}$ \\
\hline & $E^{\max }$ & Battery Capacity & $\mathrm{kWh}$ \\
\hline & $E^{\min }$ & Min SOC & $\mathrm{kWh}$ \\
\hline & $E_{\text {opt }}$ & Optimal battery SOC recommended by the manufacturer & $\mathrm{kWh}$ \\
\hline & $\zeta$ & Battery cost & $€$ \\
\hline & $\Gamma$ & Battery lifespan & years \\
\hline & $\omega$ & Battery cycles & - \\
\hline & $\alpha_{b}$ & Self-discharge of the battery & - \\
\hline \multirow{16}{*}{$\mu C H P$} & $P_{c h p}(t)$ & Power consumed by the CHP at time $\mathrm{t}$ & $\mathrm{kW}$ \\
\hline & $P_{c h p-e l e}(t)$ & Electrical power generated by the $\mu C H P$ at time $\mathrm{t}$ & $\mathrm{kW}$ \\
\hline & $P_{\text {boiler }}(t)$ & Power consumed by the boiler at time $t$ & $\mathrm{~kW}$ \\
\hline & $P_{s-c h p}(t)$ & Power exported to the grid from the $\mu C H P$ & $\mathrm{~kW}$ \\
\hline & $C_{f-c h p}$ & $\mu C H P$ electricity feed-in tariff & $€$ \\
\hline & $T_{\min }$ & Min temperature in the heat storage & Celsius \\
\hline & $T_{\max }$ & Max temperature in the heat storage & Celsius \\
\hline & $\eta_{c-h e a t}$ & Heat storage charging efficiency & - \\
\hline & $\eta_{d-h e a t}$ & Heat storage discharging efficiency & - \\
\hline & $\eta_{p-h e a t}$ & Percentage of heat from the $\mu \mathrm{CHP}$ & - \\
\hline & $C_{\text {heat }}$ & cost of heat & $€$ \\
\hline & $P_{c h p}^{\max }$ & Max power of the $\mu C H P$ & $\mathrm{~kW}$ \\
\hline & $C_{c h p}$ & $\mu C H P$ Power costs & $€$ \\
\hline & $\alpha_{h}$ & Self-discharge of the heat storage & - \\
\hline & $P_{\text {chp-heat }}(t)$ & Heat power generated by the $\mu C H P$ & $\mathrm{~kW}$ \\
\hline & $P_{c-\text { heat }}(t)$ & Heat power charged to the heat storage & $\mathrm{kW}$ \\
\hline \multirow{16}{*}{$P V / T$} & $P_{d-h e a t}(t)$ & Heat power discharged from the heat storage & $\mathrm{kW}$ \\
\hline & $P_{l-\text { heat }}(t)$ & Heat load at time $\mathrm{t}$ & $\mathrm{kW}$ \\
\hline & $H(t)$ & Heat energy storage level at time $t$ & $\mathrm{kWh}$ \\
\hline & $H_{\min }$ & Min heat energy in the heat storage device & $\mathrm{kWh}$ \\
\hline & $H_{\max }$ & Max heat energy in the heat storage device & $\mathrm{kWh}$ \\
\hline & $C_{\text {heat }}$ & cost to generate heat & $€$ \\
\hline & $P_{p v}(t)$ & Electrical power generated from the PV & $\mathrm{kW}$ \\
\hline & $P V T_{\text {heat }}(t)$ & Total solar heat generated by the PV/T & $\mathrm{kW}$ \\
\hline & $P V T_{\text {heat-used }}(t)$ & Used heat generated by the PV/T & $\mathrm{kW}$ \\
\hline & $P V T_{\text {heat-discard }}(t)$ & Discarded heat generated by the PV/T & $\mathrm{kW}$ \\
\hline & $P s-p v(t)$ & PV electricity soled to the grid at time $t$ & $\mathrm{~kW}$ \\
\hline & $C_{f-p v}$ & PV electricity feed-in tariff & $€$ \\
\hline & $\mathrm{T}$ & The optimization time horizon is (number of time steps) & - \\
\hline & $\delta$ & Time step & hour \\
\hline & $C(t)$ & Electricity price at time $t$ & $€$ \\
\hline & $P_{e}^{\max }$ & Max allowed elastic load & $\mathrm{kW}$ \\
\hline
\end{tabular}


Table 1 (continued)

\begin{tabular}{|c|c|c|c|}
\hline Component & Paramter & Summery & Unit \\
\hline & $P_{l}(t)$ & Load at time $\mathrm{t}$ & $\mathrm{kW}$ \\
\hline & $P_{e}(t)$ & Elastic load allocated at time $\mathrm{t}$ & $\mathrm{kW}$ \\
\hline & $P_{\text {phases }}(k)$ & Elastic load with $\mathrm{k}$ phases & $\mathrm{kW}$ \\
\hline & $P_{b}(t)$ & Power bought from the grid at time $\mathrm{t}$ & $\mathrm{kW}$ \\
\hline & $\beta_{1}$ & Constant & - \\
\hline & $\beta_{2}$ & Constant & - \\
\hline & $P V T_{c}$ & Cost of PV per time period & $€ /$ day \\
\hline & $\mathrm{Bat}_{c}$ & Cost of Battery per time period & $€ /$ day \\
\hline & $C H P_{c}$ & Cost of CHP per time period & $€ /$ day \\
\hline & $P V T_{O S}$ & The optimal size of the PVT & $\mathrm{kWp}$ \\
\hline & Bat $_{o s}$ & The optimal size of Battery & $\mathrm{kWh}$ \\
\hline & CHP $P_{o s}$ & The optimal size of $\mu C H P$ & $\mathrm{~kW}$ \\
\hline & EL & Elastic Load & $\mathrm{kWh}$ \\
\hline & {$\left[T_{1}, T_{2}\right]$} & Elastic Load period & hours \\
\hline
\end{tabular}

The cost of using the battery can be described as:

$C_{\text {Bat }}(t)=\beta_{1} \frac{\zeta\left|E(t)-E_{\text {opt }}\right|}{E^{\max } \Gamma}+\beta_{2} \frac{\zeta P_{d}(t)}{E^{\max } \omega}$

Two modes of operation are mainly responsible for reducing the lifespan of a battery; first keeping the battery at low SOC for long time and second the frequent charge and discharge. Therefore, the battery costs in Eq. 4 can be explained as follows. The first part represents the costs due to keeping the battery at low storage level. If the battery is kept at the lowest level for $\Gamma$ hours, the battery will not be useable (the value of the battery will be 0 and the cost will be $\zeta$ ). For example, for a $5 \mathrm{kWh}$ battery (and optimal SOC is $5 \mathrm{kWh}$ ) with 3 years lifespan if the battery is hold at $0 \mathrm{kWh}$ $\mathrm{SOC}$, then after one hour at $0 \mathrm{~kW} \mathrm{SOC}$, the value of the battery will be reduced by $\frac{1}{3 * 365 * 24}$. It is important to say, that holding the SOC of the battery at $1 \mathrm{kWh}$ lower than the optimal SOC for 5 hours doesn't have the same effect as holding the battery at $0 \mathrm{kWh} \mathrm{SOC}$ for 1 hour. Therefore $\beta_{1}$ is usually less than one. The second part of Eq. 4 is for limiting the number of charging and discharging operations. A battery with $\omega$ cycles can be discharged from full to empty $\omega$ times. Therefore, the value of the battery will be 0 and hence the cost is $\zeta$ if the battery has been discharged $\omega \times E^{\max } k W h$. For example, consider a $5 \mathrm{kWh}$ battery with discharge capability of $1 \mathrm{~kW}$ and 1200 cycles, then after $\frac{5}{1} \times 1200$ hours of discharging, the value of the battery will be 0 . In other words, discharging the battery with $1 \mathrm{~kW}$ over one hour reduces the value of the battery by $\frac{1}{5 \times 1200}$. Of course, this is the worst case, i.e., continued discharging until the battery is empty. However, doing charging and discharging on high
SOC levels will cause lower cost and hence $\beta_{2}$ is usually less than one. We assume here that the optimal value of the state of charge is provided by the manufacturer and hence the optimization approach will try to keep the battery SOC near this value. In the simulation it is assumed $65 \%$ (i.e. $3.25 \mathrm{kWh}$ ) is the optimal value of SOC of a $5 \mathrm{kWh}$ battery.

The above maximization problem is subject to system constraints. We consider the electrical balance constraints which can be written as:

$$
\begin{array}{r}
P_{p v}(t)+P_{d}(t)-P_{e}(t)-P_{l}(t)+P_{c h p-e l e}(t)-P_{c}(t) \\
+P_{b}(t)-P_{s-p v}(t)-P_{\text {boiler }}(t)-P_{s-c h p}(t)=0
\end{array}
$$

We consider also the heat power balance. The following equation represents the fact that the heat can only be discharged from the heat storage unit.

$P_{d-\text { heat }}(t)-P_{l-\text { heat }}(t)=0$

The solar heat used $P V T_{\text {heat-used }}(t)$ and discarded $P V T_{\text {heat-discard }}(t)$ sum up to the total heat $P V T_{\text {heat }}(t)$ generated by the PV panel.

$P V T_{\text {heat-used }}(t)+P V T_{\text {heat-discard }}(t)=P V T_{\text {heat }}(t)$

The following equation describes the inputs of the heat storage unit. Here we assumed that the efficiency of the energy conversion from electricity to heat for the boiler is $100 \%$.

$$
\begin{array}{r}
P V T_{\text {heat-used }}(t)+P_{\text {chp-heat }}(t)+P_{\text {boiler }}(t)= \\
P_{c-\text { heat }}(t)
\end{array}
$$


The energy balance in the battery can be modeled as:

$$
\begin{aligned}
& E(t+1)-\left(1-\alpha_{b}\right) E(t)+\delta \frac{P_{d}(t)}{\eta_{d}}-\delta \eta_{c} P_{c}(t)=0 \\
& E^{\text {max }} \geq E(t) \geq E^{\text {min }}
\end{aligned}
$$

The same principle can be used to model the heat storage unit:

$$
\begin{aligned}
& H(t+1)-\left(1-\alpha_{h}\right) H(t)+\delta \frac{P_{d-\text { heat }}(t)}{\eta_{d-\text { heat }}} \\
& -\eta_{c-\text { heat }} \delta P_{c-\text { heat }}(t)=0 \\
& H_{\text {max }} \geq H(t) \geq H_{\text {min }}
\end{aligned}
$$

The temperature inside the heat storage unit should stay between two temperatures $T_{\min }$ and $T_{\max }$ and hence the heat energy must stay between the two heat energy levels $H_{\text {min }}$ and $H_{\max }$. Equations 13 and 14 present a mathematical model for the $\mu C H P$.

$P_{c h p-h e a t}(t)+P_{c h p-e l e}(t)=P_{c h p}(t)$

$\frac{P_{\text {chp-heat }}(t)}{\eta_{p-h e a t}}-\frac{P_{\text {chp-ele }}(t)}{1-\eta_{p-\text { heat }}}=0$

where $\eta_{p-h e a t}$ denote the percentage of power converted to heat and hence $\left(1-\eta_{p-h e a t}\right)$ of the energy will be converted to electricity. We have also considered the following limitations in the system:

$$
\begin{aligned}
& P_{d}^{\max } x(t) \geq P_{d}(t) \\
& P_{c}^{\max }(1-x(t)) \geq P_{c}(t) \\
& P_{e}^{\max } \geq P_{e}(t) \\
& x(t) \in\{0,1\} \\
& P_{c h p}^{\max } \geq P_{\text {chp }}(t)
\end{aligned}
$$

The discrete value of $x(t)$ can be 0 or 1 . In each time slot, the battery is either in charge (0) or discharge (1) state.

The elastic load $E L$ should be served in a specific period, which can be written as:

$$
\sum_{t=T_{1}}^{T_{2}} \delta P_{e}(t)=E L
$$

where $\left[T_{1}, T_{2}\right]$ is the period where the elastic load should be run. In the simulation experiments, we set $T_{1}=0$ and $T_{2}=T$. If the load should be carried out continuously and it consists of several phases (e.g., washing machine), the following constraints should be added.

$$
\begin{gathered}
y(t)+w(t) \geq w(t-1) \\
y(t) \geq y(t-1) \\
P_{e}(k)=w(k) P_{\text {phases }}(k) \quad \forall k \\
w(t) \in\{0,1\}
\end{gathered}
$$

\section{Evaluation}

\section{Simulation Environment}

We have used the simulation toolbox presented in [4-6, $8,9]$ which is based on the AnyLogic [2] simulator. To build the simulation model of the electrical and heat components such as $P V, \mu C H P$, and demand models as well as models for communication components, we have extended the components of the toolbox. Additionally, we relied on MATLAB [23] to solve the optimization problem. The data exchange between MATLAB and AnyLogic is done through a proxy. The simulation model defines first the topology of the smart grid which includes the power as well as the communication infrastructures. The main building blocks of these topologies are node modules (houses), which include models for electricity demand (e.g., refrigerator), supply (e.g., PV) as well as storage (e.g., battery).

For the electricity demand profiles, the mean energy consumption of households is used. Out of these profiles values are sampled and superimposed with stochastic functions to model the stochastic behavior of a single household [20]. For the solar model module, a solar insolation model is required. This model is implemented according to [24]. Weather profiles are used and superimposed with stochastic functions.

Figure 2a shows the profile used to compute the electricity and heat demand during a day in winter. The peak demand hours occur when people return back from work (e.g., after $4 \mathrm{pm}$ ). Figure $2 \mathrm{~b}$ depicts the normalized insolation of a typical day. The solar irradiation with respect to each month of a year is obtained from the weather profiles by applying monthly scaling factors. As it can be seen, it is possible to generate electricity only from 9 am to$17 \mathrm{pm}$.

Table 2 summarizes the used parameters in this case study. The default value for both charge and discharge efficiency is 0.77 [3]. We used different scenarios to explore our method. We compared the results with an approach in which a house tries to achieve self-sufficiency. Upon receiving the day-ahead price, the controller at the house sends the 
Fig. 2 Typical daily electricity and heat demand in winter (a) and solar insolation curve (b)

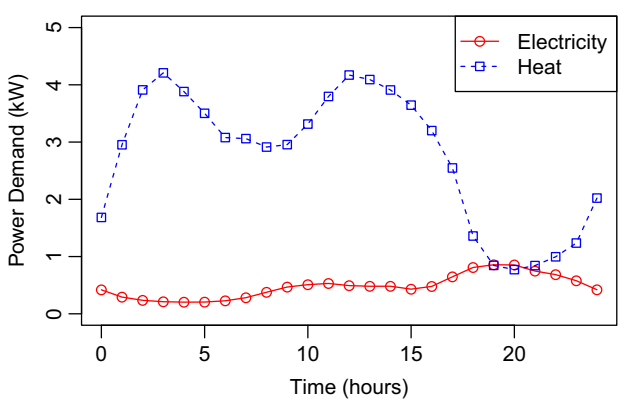

(a)

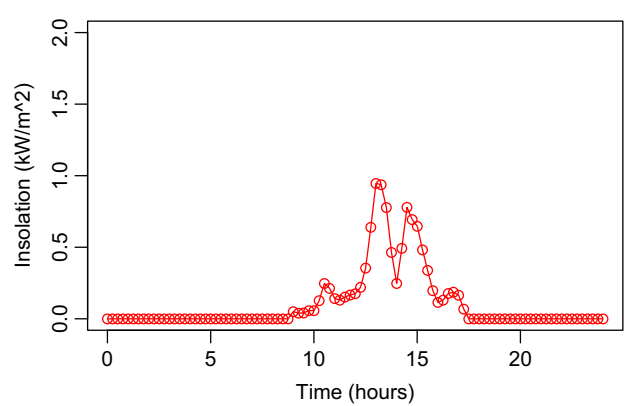

(b) data to a solver which in turn sends back the optimal operating parameters. The controller repeats this process hourly and therefore it can mitigate the influence of uncertainty in the demand and supply forecasts.

\section{Day-ahead Price}

To simulate the dynamic nature of the day-ahead electricity prices, we relied on real historical data from the European Energy Exchange in Leipzig as in [4-6]. We developed two types of markets to show a variable end-user electricity price. The main goal of these markets is to try to answer the following question: If there were day-ahead prices available for end-users, how would they look like? The first market tries to reflect demand/supply on the price while the other market tries to use real data to figure out the day-ahead price.

\section{Simple Market}

In the first electricity market we used the difference between demand and supply in the network to figure out the dayahead price, i.e., high demand leads to high price and low demand leads to low price. In this simple electricity market, every controller sends hourly its forecasted amount of energy demand and supply for the rest of the day to the server. With the received data and electricity price limits as in $[4,5]$, the server calculates the day ahead price and sends it to the consumers. To simulate variable electricity prices, a simplified representation of the electricity market is used
Table 2 Parameters used in the simulation, default parameters are in parentheses

\begin{tabular}{|c|c|}
\hline$\delta$ & (1 hour) \& $15 \mathrm{~min}$ \\
\hline Efficiency charge/discharge of Battery & $(77 \%), 90 \%$ \\
\hline$P_{c}^{\max }, P_{d}^{\max }$ & $1 \mathrm{~kW}$ \\
\hline Max extra load $P_{e}^{\max }$ & $1 \mathrm{~kW}$ \\
\hline Storage Capacity $E^{\max }$ & $1,2.5,(5), 10 \mathrm{kWh}$ \\
\hline Network Size & 20 \\
\hline Area of Solar Module & $10 \mathrm{~m}^{2},\left(20 \mathrm{~m}^{2}\right), 40 \mathrm{~m}^{2}, 80 \mathrm{~m}^{2}$ \\
\hline Efficiency of Solar Module (Electricity) & 0.1 \\
\hline Efficiency of Solar Module (Heat) & 0.7 \\
\hline Elasticity & $(0 \%), 5 \%, 10 \%, 20 \%, 2 \mathrm{kWh}$ \\
\hline Battery Cost & $(0), 100 € / \mathrm{kWh}, 140 € / \mathrm{kWh}$ \\
\hline$\left(T_{\min }, T_{\max }\right)$ & $55,85 \mathrm{C}$ \\
\hline$\eta_{d-h e a t}, \eta_{c-h e a t}$ & $100 \%$ \\
\hline$\eta_{p-h e a t}$ & $70 \%$ \\
\hline$P_{\text {chp }}^{\max }$ & $4 \mathrm{~kW}$ \\
\hline$\alpha_{h}$ & $2 \%$ \\
\hline$\alpha_{b}$ & $0 \%$ \\
\hline$C_{f-p v}$ & $(0.18) \& 0.1 €$ \\
\hline$C_{f-\operatorname{chp}}(t)$ & $0.09 €$ \\
\hline$C_{c h p}$ & $0.07 €$ \\
\hline Electricity Market & (Simple Market), EEX-Market \\
\hline
\end{tabular}


Table 3 Summary of the different unit costs

\begin{tabular}{llll}
\hline Component & Cost & Typical Size & Life Span \\
\hline PV/T & $3000 € / \mathrm{kWp}$ & $1-30 \mathrm{~kW}$ & 20 years \\
Battery & $140 € / \mathrm{kWh}$ & $1-20 \mathrm{kWh}$ & 4 years \\
$\mu C H P$ & $4000 € / \mathrm{kW}$ & $1-20 \mathrm{~kW}$ & 18 years \\
\hline
\end{tabular}

in the model. The server uses the history of the difference between residual demand and supply (Demand - Supply) to determine the price such that the maximum difference corresponds to the maximum price and the minimum corresponds to the minimum price. The electricity price changes during the day depending on the actual demand and supply, therefore the server sends day-ahead electricity prices to the consumers every 24 hours.

\section{EEX-based Market}

In the second market we used the electricity price at EEX for the whole year 2014 to extract the end user day-ahead price. We used the following equation to find the end-user electricity price:

$$
\begin{aligned}
& K=\frac{0.1387}{\operatorname{Pr} E E X_{\text {avg }}} \\
& P r=(K * \operatorname{PrEEX}+0.0179+0.0205+0.0018 \\
& +0.0624+0.0009+0.0025+0.0001) \times 1.19(25
\end{aligned}
$$

where 0.1387 is the price of electricity in Germany due to electricity production, transportation and sales in 2014 [10]. $\operatorname{PrEEX} X_{\text {avg }}$ is the average electricity price at EEX during 2014. The 0.0179 is the concession fee, 0.0205 is the electricity tax. The values $0.0018,0.0624,0.0009,0.0025$, and 0.0001 correspond to the CHP, EEG, §19, offshore, and AbLaV apportionment, respectively. The value 1.19 includes the 0.19 VAT. Figure 5a shows the electricity price in the first week of January, March, June and September. The average price during the whole year is $0.29 € / \mathrm{kWh}$ which is in line with the average electricity price for households in Germany in the year 2014 [10].

We performed four sets of experiments to explore the effect of different parameters on the savings. We started with a simple setup where we considered only a system with PV and Battery. Then we explored the effect of battery costs and optimal usage of the battery. After that we investigated a more complex system where we included PV/T and $\mu C H P$. Final we explored the effect of uncertainty of the demand forecast.

\section{Optimal System Setup}

Before we investigate the optimal coordination and its effects on savings, we perform economic analysis to find the optimal sizes of the units. Inputs for the economic calculations are the heat and electricity demand and investment costs for solar PV/T, battery, and $\mu C H P$. We used an elec-

\begin{tabular}{|c|c|c|c|}
\hline Setup & Component & Size & Notes \\
\hline & $\mathrm{PV} / \mathrm{T}$ & $9.8 \mathrm{kWp}$ & \\
\hline \multirow[t]{9}{*}{ Stand Alone } & Battery & $10.2 \mathrm{kWh}$ & \\
\hline & $\mu C H P$ & $4.1 \mathrm{~kW}$ & \\
\hline & $\mathrm{PV} / \mathrm{T}$ & $10.3 \mathrm{kWp}$ & PV feed-in tariff \\
\hline & Battery & $3.9 \mathrm{kWh}$ & $0.1 € / \mathrm{kWh}$ \\
\hline & $\mu C H P$ & $4.0 \mathrm{~kW}$ & \\
\hline & $\mathrm{PV} / \mathrm{T}$ & $30 \mathrm{kWp}$ & PV feed-in tariff \\
\hline & Battery & $1.8 \mathrm{kWh}$ & $0.18 € / \mathrm{kWh}$ \\
\hline & $\mu C H P$ & $4.0 \mathrm{~kW}$ & \\
\hline & $\mathrm{PV} / \mathrm{T}$ & $10.5 \mathrm{kWp}$ & PV feed-in tariff \\
\hline \multirow[t]{8}{*}{ Grid Connected } & Battery & $4.6 \mathrm{kWh}$ & $0.1 € / \mathrm{kWh}$ \\
\hline & $\mu C H P$ & $4.0 \mathrm{~kW}$ & flat-rate electricity price $0.29 € / \mathrm{kWh}$ \\
\hline & $\mathrm{PV} / \mathrm{T}$ & $3.7 \mathrm{kWp}$ & PV feed-in tariff \\
\hline & Battery & $2.3 \mathrm{kWh}$ & $0.1 € / \mathrm{kWh}$ \\
\hline & $\mu C H P$ & $4.9 \mathrm{~kW}$ & Winter \\
\hline & $\mathrm{PV} / \mathrm{T}$ & $30 \mathrm{kWp}$ & PV feed-in tariff \\
\hline & Battery & $2.4 \mathrm{kWh}$ & $0.1 € / \mathrm{kWh}$ \\
\hline & $\mu C H P$ & $0.23 \mathrm{~kW}$ & Summer \\
\hline
\end{tabular}

Table 4 The Optimal Size of the Different Components 
Fig. 3 Hourly profit during a day (a) and daily profit difference for different panel sizes $(\mathbf{b})$

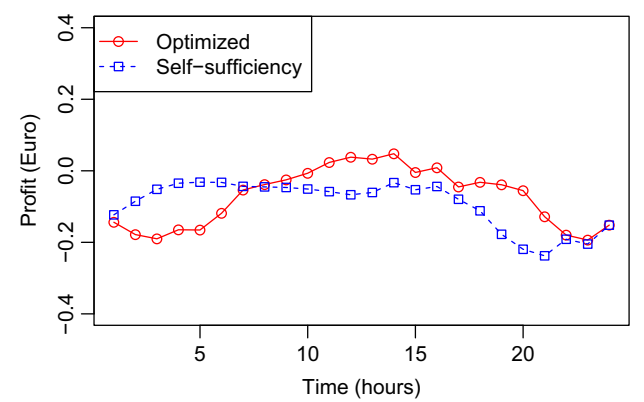

(a)

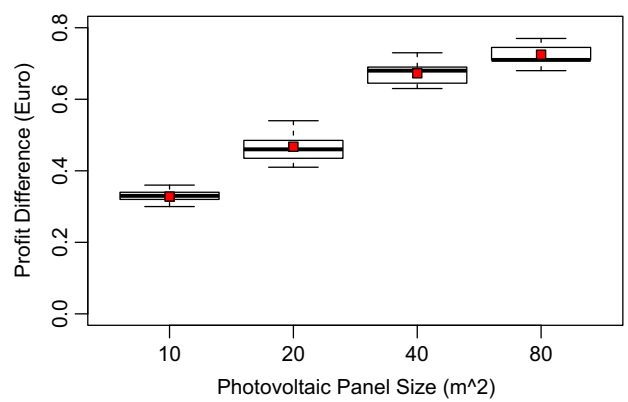

(b) tricity demand for a typical family in Germany and a typical PV electricity profile in Germany. Table 3 summarizes the costs of the different elements.

We add the costs of the different components to the objective function in 3 as shown in Eq. 26

$$
\begin{aligned}
& \max \sum_{t=0}^{T}\left(C_{f-p v} \delta P_{s-p v}(t)+C_{f-c h p} \delta P_{s-c h p}(t)\right. \\
& \left.-C(t) \delta P_{b}(t)-C_{c h p}(t) \delta P_{c h p}(t)\right) \\
& +C_{h e a t} H(T)+C(T) \eta_{d} E(T)-P V T_{c} P V T_{o s} \\
& -B a t_{c} B a t_{o s}-C H P_{c} C H P_{o s}
\end{aligned}
$$

Table 4 shows typical results of the optimal size for different setup scenarios. These results do not take into consideration any degradation in the performance of the units. The stand alone case represents a situation where the connectivity to a grid can be difficult, which can be suitable for rural areas and farms. In this case, $9.8 \mathrm{kWp} \mathrm{PV/T,} \mathrm{10.2} \mathrm{kWh} \mathrm{Battery} \mathrm{as}$ well as $4.1 \mathrm{~kW}$ CHP are enough to cover the electricity and heat loads. In case of low feed-in tariff, a battery with size $3.9 \mathrm{kWh}$ was enough to cope with the demand. With high feed-in tariff, the maximum allowed value $(30 \mathrm{~kW})$ is the optimal size of PV/T to maximize the profit. A flat-rate electricity price has no significant influence on the unit sizes, nevertheless, a larger battery is required. We ran the simulation for one month in winter (January) and one month in summer (June). As can be expected, if we consider only winter weather, there is no need for a large $\mathrm{PV} / \mathrm{T}$ and a larger $\mu C H P$ is more profitable. On the other side, if we consider only summer weather, then a large $\mathrm{PV} / \mathrm{T}$ is more profitable and only a very small CHP will be needed (to cover the low heat demand).

\section{Savings Due to Electricity Management Excluding Battery Costs}

At the beginning we start by considering only the electricity and excluding the heat energy. Additionally, we used the load models as described in $[4,5,8]$. The feed-in tariff for PV electricity is $0.18 € / \mathrm{kWh}$.

Figure 3a depicts the average profit of a house connected to the network at different time slots during a day. As the figure shows, the optimized approach has lower profit at early-morning hours because it buys more energy from the network than the local demand (because the electricity price at this time is cheap). The extra energy is stored in the battery for future use. Of course, the controller made this decision because it knows from the forecast that the house has a specific demand in the future and the electricity prices are going to be higher. When the PV provides energy, the optimized approach is able to sell more energy than the selfsufficiency approach, i.e., it uses the power in the battery to cover the local load when the electricity price is high. Figure $3 \mathrm{~b}$ shows the daily profit difference for different
Fig. 4 Daily profit difference for different battery capacities (a), and daily profit difference due elasticity (b)

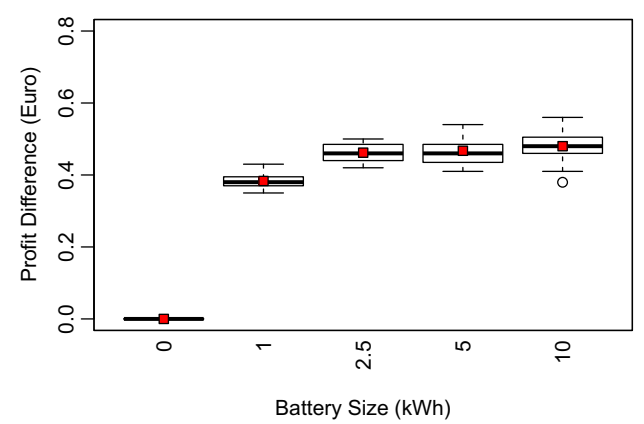

(a)

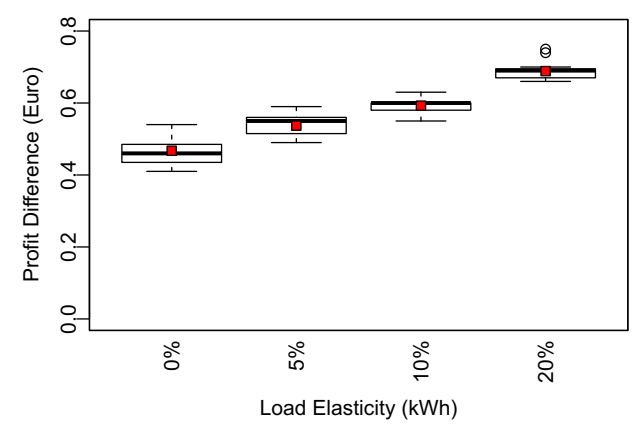

(b) 
Fig. 5 Electricity price in the first week of January, March, June and September in 2014 using Eq. 25 (a) and battery SOC for self-sufficiency and optimized approach when the cost is $0,100 € / \mathrm{kWh}$, and 140 $€ / \mathrm{kWh}(\mathbf{b})$

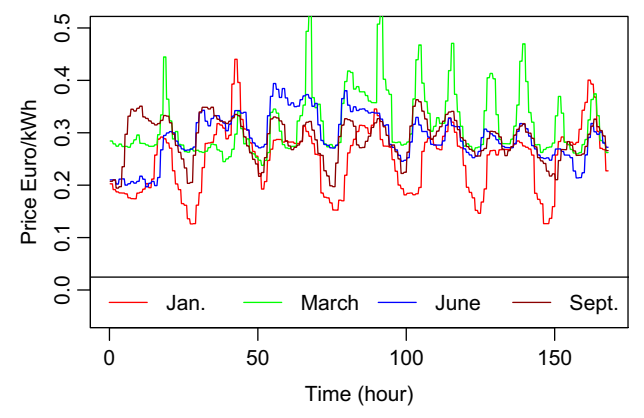

(a)

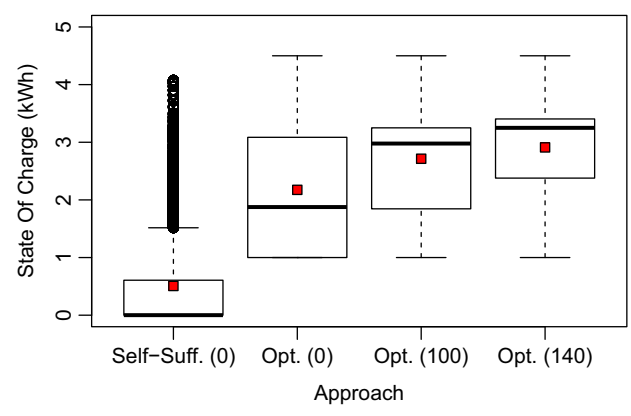

(b) solar panel sizes. As can be expected, increasing the panel size increases the profit difference, reflecting a better power management for the available energy.

We explored also the impact of battery size on the profit. First we ran experiments without battery and then we ran several experiments with storage capacities of 1, 2.5, 5 and $10 \mathrm{kWh}$. At this point we did not consider elastic loads, therefore, as can be seen in Fig. 4a, without a battery the optimized approach has no benefit over the self-sufficiency one. Both will have the same behavior such that both approaches will buy energy when the supply is less than the demand and sell energy when the generated energy exceeds the demand. At the beginning, the profit of the optimized approach increases as the size of the battery increases. It is not allowed to sell energy from the battery, therefore a capacity of $2.5 \mathrm{kWh}$ was sufficient to deal with the demand and energy supply of a house and hence any further power storage capacity is not required.

Figure $4 \mathrm{~b}$ shows the savings due to shifting loads partially. As it can be seen, the savings increase as we increase the elastic load. The controller uses the day-ahead price, supply forecast and load forecast to find the appropriate time slot to allocate the elastic load.

\section{Savings Due to Electricity Management Including Battery Costs}

In this set of experiments we use the EEX-market, in which the electricity price is taken from EEX for the whole year (2014). We used a standard load profile with annual consumption of $3500 \mathrm{kWh}$ and PV supply profile with 2000 $\mathrm{kWh}$. The house has a $5 \mathrm{kWh}$ battery and $2 \mathrm{kWh}$ elastic load. The profiles provide time resolution of $15 \mathrm{~min}$, therefore the time step of the simulation is set to $\delta=15 \mathrm{~min}$. In this set of experiments the feed-in tariff for PV electricity is $0.1 €$. We used the technical specifications of the battery IND33-2V with two different prices; $100 € / \mathrm{kWh}$ and $140 € / \mathrm{kWh}$ (the current price is about $140 € / \mathrm{kWh}$ ). IND33-2V is a flooded lead-acid battery intended for the use in PV systems [16]. We set $\beta_{1}$ and $\beta_{2}$ to 0.5 , lifespan $\Gamma$ to 3 years and $\omega$ to 1200 cycles. It is assumed that $3.25 \mathrm{kWh}$ is the optimal SOC $\left(E_{o p t}\right)$ and SOC should not drop below $1 \mathrm{kWh}$. Figure $5 \mathrm{~b}$ shows that the SOC of the self-sufficiency approach is very low compared to the optimized approach even if the battery cost has been not included. When the battery costs were included in the optimization problem, the SOC tends to be near $E_{\text {opt }}$. We found that the amount of energy discharged from the battery when applying self-sufficiency is slightly lower compared to the optimized approach. The main reason is that the optimized approach attempts to buy energy when it is cheap in order to use it later when the electricity is expensive. With all values of battery costs, the optimized approach was able to increase the profit in addition to maintain the SOC of the battery near the optimal SOC. All in all, with the optimized approach, it is possible to save money by importing and exporting energy as well as by extending the
Fig. 6 Annual profit from a system that includes $\mu \mathrm{CHP}$ and $P V / T$ (a), electricity generated by the $\mu C H P$ and exported to the grid (b)

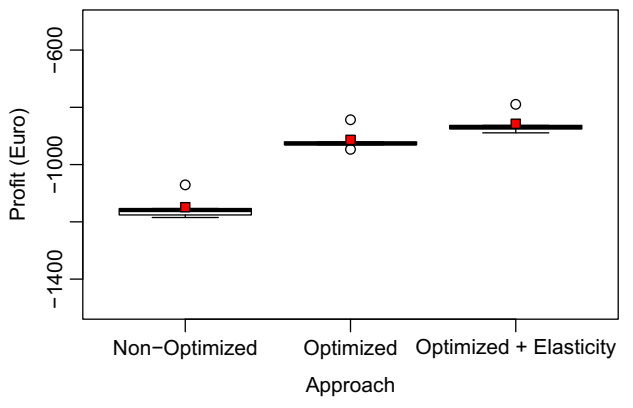

(a)

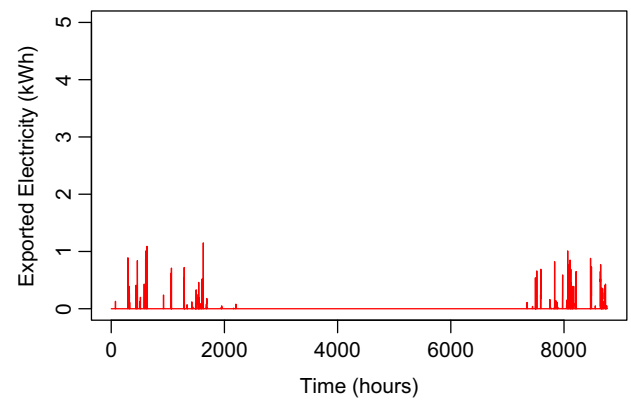

(b) 
Fig. 7 Evolution of gas consumption by the $\mu C H P$ in winter (a) and summer (b)

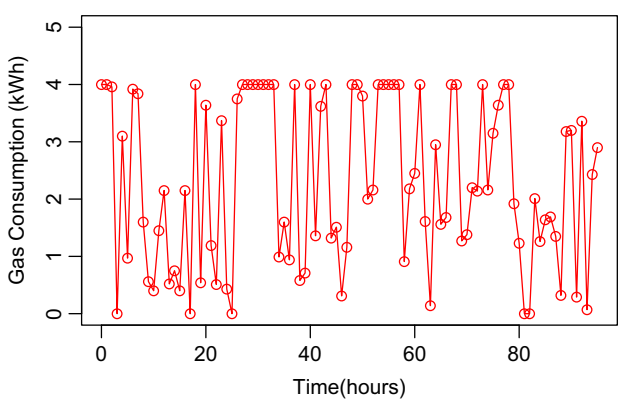

(a)

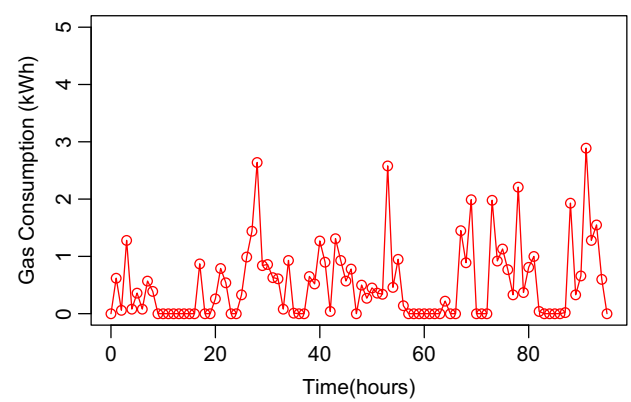

(b) lifespan of the battery.

\section{Savings Due to Electricity and Heat Management}

In this set of experiments we explored the savings when including $\mu \mathrm{CHP}$ and heat demand. We used the load profiles for heat and electricity shown in Fig. 2. We set the heat storage size to 120 liters and the heat energy inside the heat storage unit must stay in the range between 4.9 and 8.5 $\mathrm{kWh}$. We assumed that the $\mu C H P$ runs on gas and that one $\mathrm{kWh}$ generated by the $\mu C H P$ costs $0.07 €$. The feed-in tariff for the $\mu C H P$ electricity is $0.09 €$. Figure 6a presents the profit when including a $\mu C H P$ in the system. As can be seen, the annual savings difference between the optimized and non optimized approach is about $300 €$. The savings will increase slightly if we assumed that $20 \%$ of the electrical load is shiftable during the day. The main reason why there is no significant difference on the saving due to elasticity is that the electricity produced by $\mu C H P$ is cheap compared to the electricity bought from the power grid.

Figure $6 \mathrm{~b}$ shows the amount of electricity that has been produced by the $\mu C H P$ and exported to the power grid. The compensation for electricity produced by the $\mu C H P$ and fed to the grid is lower than the feed-in tariff for PV and the price of electricity bought from the power grid. Therefore, the only situation where the electricity produced by the $\mu$ CHP will be exported to the network is when the local electricity demand is already covered and the battery is full. This situation can occur in winter, when the $\mu C H P$ is used heavily to cover the heat demand.

Figure $7 \mathrm{a}$ and $\mathrm{b}$ show the gas consumption by $\mu \mathrm{CHP}$ to supply heat and electricity in winter and summer, respectively. As can be expected, the $\mu C H P$ provides less energy in summer.

\section{Electricity Demand Estimation}

An important component for the optimization of energy management systems is the availability of forecasts for energy supply and demand. Several methods can be utilized to estimate the demand. In this sub-section we present a method using artificial neural networks to estimate the demand and then we study the effect of deviation from the real values on the performance of our approach. This set of experiments is based on the standard load profile 'Standardlastprofil' from EON [18]. We used load profiles from previous years to train the neural network and then we evaluated the approach with load profiles from the actual year. The demand was estimated by applying a feed-forward artificial neural network (Fig. 8a), which is widely used for forecast purposes. We used the neural network toolbox in MATLAB to build the network with 6 inputs; hour, minute,
Fig. 8 Feed-forward artificial neural network (a) and daily profit difference during different days using an artificial neural network for demand forecast (b)

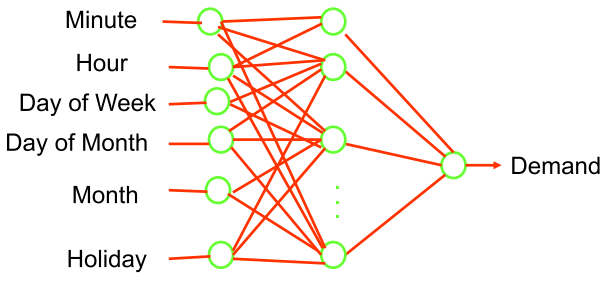

(a)

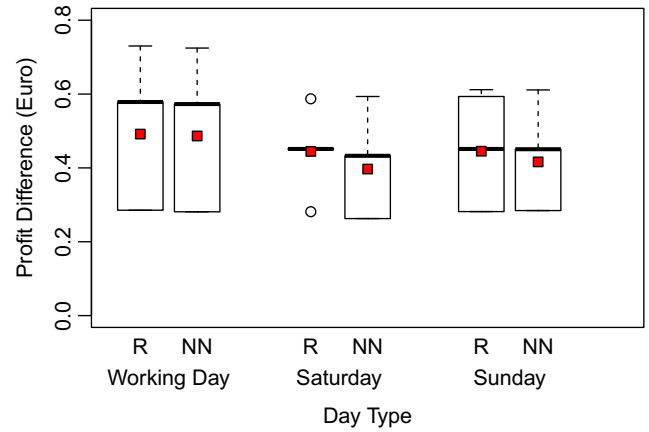

(b) 
Fig. 9 Comparison of electricity demand forecast for a working day (a) and holiday (Sunday) (b)

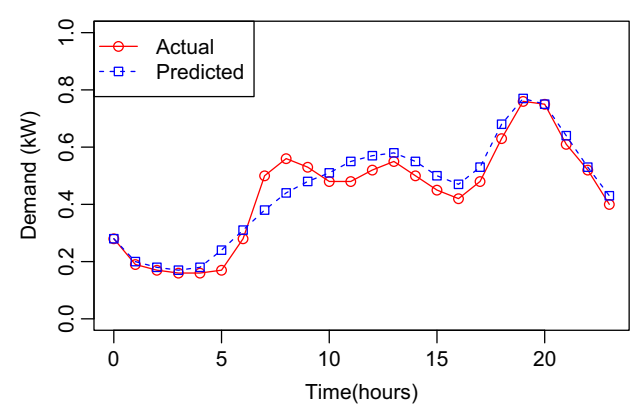

(a)

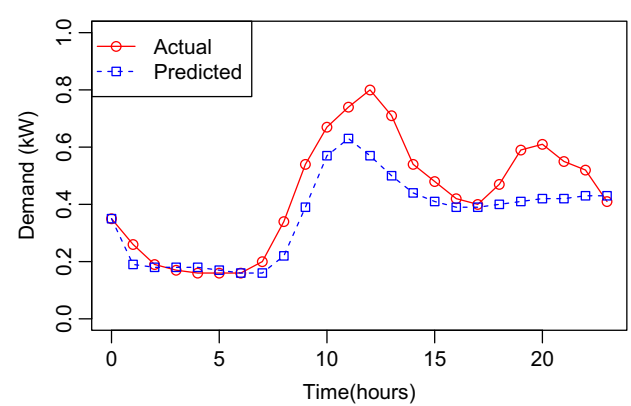

(b) day of week, day of month, month, and holiday. The holiday input has a value of zero or one to indicate if the day is a holiday or not. There are 5 nodes in the first hidden layer, 15 nodes in the second hidden layer, and one node in the output layer. The impact of estimation on the results is presented in Fig. 8b where R represents the actual demand and $\mathrm{NN}$ represents the results when the artificial neural network is used to estimate the demand. As can be seen, the impact of the forecast error is not significant. Moreover, the process is repeated each time step, which mitigate the impact of forecast errors. The comparison between the estimated and actual demand (Fig. 9) shows that the network is able to estimate the demand during a working day with less errors than on weekend or holiday.

\section{Limitations}

The main limitation of the model is simplification of some components. For instance, all models are linear; e.g., the investment costs are considered as linear. The simulation model of the battery is very simple and it does not take into consideration parameters such as temperature and the effect of the SOC on the charging and discharging power. Another simplification is the electricity market. In our approach, neither the time value of money nor the correlations between weather, PV generation, and demand have been considered. Moreover, the electricity market modeling approach is strongly simplified. Additionally, the simulation model of the $\mu C H P$ is also simple and therefore it does not include issues such as power ramps. The PV model does not consider the outside temperature. Furthermore, the neural network was trained off-line only. The main reason behind these simplification is to keep the system linear and hence easy to be implemented inside an embedded micro-controller (i.e., inside the smart meter). In fact, a dynamic (nonlinear) model for a battery would be necessary if network dynamics are going to be studied. If energy providers want to use a price-based DR program and motivate the people to shift their demand from high demand period to low demand periods, they should provide a variation in the price that makes the load re-allocation profitable. Therefore, we employed a method that makes the household electricity price signal to have a similar shape as at the EEX market.

\section{Discussion and Conclusions}

We presented a technologically concentrated approach to maximize the profit of privately owned $\mathrm{PV} / \mathrm{T}$ and $\mu \mathrm{CH} P$ hybrid power systems. The optimization problem is formulated as linear programming which makes it easy to be implemented inside a smart meter or in an energy management controller. The approach requires forecasts for demand and supply. At the beginning we assumed that these forecasts are available through services from an external system. In an extensive simulation-based performance evaluation, we assessed the impact of battery size, the panel size, and demand elasticity on the profit maximization. We compared the savings of the proposed optimization approach with a self-sufficiency approach. The results clearly demonstrate the possibility to enhance the profit when applying the optimized approach. The results show also that a larger battery does not necessarily yield more savings. This is due to the fact that it is not allowed to resell the energy bought from the grid. We then included the cost of the battery such that the battery SOC remains near the optimal SOC recommended by the manufacturer. Additionally, the battery cost term prevents unnecessary charge and discharge operation. Furthermore, we introduced an artificial neural network as a candidate for demand estimation and the results show that the estimation error has no significant impact on the savings. The reason behind that is mainly because the approach depends heavily on the day-ahead price, which has no 
error. Additionally, it is sufficient to know the trend of the demand, i.e. low demand in the midday and high demand in the early evening.

Acknowledgments Peter Bazan is also a member of "Energie Campus Nürnberg", Fürther Str. 250, 90429 Nürnberg. His research was performed as part of the "Energie Campus Nürnberg" and supported by funding through the "Aufbruch Bayern (Bavaria on the move)" initiative of the state of Bavaria.

\section{References}

1. Alfares HK, Nazeeruddin M (2002) Electric load forecasting: literature survey and classification of methods. 33(1)

2. Anylogic (2013) Xj technologies company ltd. http://www.xjtek. com/. [Online; accessed 20-January-2013]

3. Atwa YM, El-Saadany EF (2010) Optimal Allocation of ESS in Distribution Systems With a High Penetration of Wind Energy. IEEE Transactions on Power Systems 25(4):18151822

4. Awad A, Bazan P, German R (2012) Exploiting Day-Ahead Electricity Price for Maximized Profit of Photovoltaic Systems. In: Proceedings of the IEEE International Conference on Smart Grid Technology. Nuremberg

5. Awad A, Bazan P, German R (2013) Profit Enhancement Through Optimized Operation of Photovoltaic Systems with Elastic Demand. In: Proceedings of the IEEE PES Asia-Pacific Power and Energy Engineering Conference 2013 (IEEE PES APPEEC 2013). IEEE, Hong Kong

6. Awad A, Pruckner M, Bazan P, German R (2014) On the Profit Enhancement and State Estimation Services in the Smart Grid. In: Proceedings of the IEEE PES Innovative Smart Grid Technologies Conference (ISGT 2014). IEEE, Washington

7. Azadeh A, Faiz ZS (2011) A meta-heuristic framework for forecasting household electricity consumption. Appl Soft Comput 11(1):614-620

8. Bazan P, German R (2012) Hybrid Simulation of Renewable Energy Generation and Storage Grids. In: Winter Simulation Conference. Berlin

9. Bazan P, Luchscheider P, German R (2015) Rapid Modeling and Simulation of Hybrid Energy Networks. In: Proceedings of the 2015 SmartER Europe Conference. Essen, Germany

10. BDEW (2014) BDEW-Strompreisanalysen Juni 2014: Haushalte und Industrie. BDEW, Berlin

11. Bertsch V, Schwarz H, Fichtner W, Huisman D, Louwerse I, Wagelmans AP (2014) Layout optimisation of decentralised energy systems under uncertainty Operations Research Proceedings 2013, Operations Research Proceedings, pp. 29-35. Springer International Publishing. doi:10.1007/978-3-319-07001-8_5

12. Capuder T, Mancarella P (2014) Techno-economic and environmental modelling and optimization of flexible distributed multigeneration options. Energy 71:516-533

13. Castillo-Cagigal M, Caamaño-Martín E, Matallanas E, Masa-Bote D, Gutiérrez A, Monasterio-Huelin F, Jiménez-Leube J (2011) PV self-consumption optimization with storage and Active DSM for the residential sector. Sol Energy 85(9):2338-2348

14. Castronuovo E, Lopes JAP (2009) Optimal operation for a windhydro power plant to participate to ancillary services. In: Proceedings of the 2009 IEEE International Conference on Industrial Technology, ICIT '09. IEEE Computer Society, Washington, pp 15
15. Chen X, Wei T, Hu S (2013) Uncertainty-aware household appliance scheduling considering dynamic electricity pricing in smart home. IEEE Transactions on Smart Grid 4(2):932-941

16. Company T (2013) Energy Storage Solutions for Renewable Energy and Backup Power. http://www.trojanbatteryre.com/pdf/ trjn0159_reseriescoll.pdf

17. Crespo Del Granado P, Wallace S, Pang Z (2014) The value of electricity storage in domestic homes: a smart grid perspective. Energy Syst 5(2):211-232. doi:10.1007/s12667-013-0108-y

18. E.ON Mitte AG. E.ON Mitte AG. http://eon-mitte.com/ (2013). [Online; accessed 14-March-2013]

19. Erdinc O (2014) Economic impacts of small-scale own generating and storage units, and electric vehicles under different demand response strategies for smart households. Appl. Energy 126:142150

20. Houwing M, Negenborn R, De Schutter B (2011) Demand response with micro-CHP systems. Proc IEEE 99(1):200-213. doi:10.1109/JPROC.2010.2053831

21. Koussa M, Malek A, Haddadi M (2009) Statistical comparison of monthly mean hourly and daily diffuse and global solar irradiation models and a simulink program development for various algerian climates. Energy Convers Manag 50(5):1227-1235

22. Matallanas E, Castillo-Cagigal M, Gutiérrez A, MonasterioHuelin F, Caamaño-Martín E, Masa D, Jiménez-Leube J (2012) Neural network controller for Active Demand-Side Management with PV energy in the residential sector. Appl Energy 91(1):90-97

23. MathWorks. Mathworks. http://www.mathworks.de/ (2013). [Online; accessed 20-January-2013]

24. Mazhari EM, Zhao J, Celik N, Lee S, Son YJ, Head L (2009) Hybrid simulation and optimization-based capacity planner for integrated photovoltaic generation with storage units. In: Winter Simulation Conference. Austin, Texas

25. Modica GD, d'Entremont R, Mlawer E, Gustafson G (2010) Short-range solar radiation forecasts in support of smart-grid technology. In: American Meteorological Society Conference

26. Mohsenian-Rad AH, Wong V, Jatskevich J, Schober R, LeonGarcia A (2010) Autonomous demand-side management based on game-theoretic energy consumption scheduling for the future smart grid. IEEE Transactions on Smart Grid 1(3):320-331. doi:10.1109/TSG.2010.2089069

27. Nguyen Ngoc PD, Pham TTH, Bacha S, Roye D (2004) Bounding active power generation of a wind-hydro power plant. In: Proceedings International Conference on Probabilistic Methods Applied to Power Syst. IEEE Computer Society, Washington, pp 705-710

28. Palensky P, Dietrich D (2011) Demand Side Management: Demand Response, Intelligent Energy Systems, and Smart Loads. IEEE Trans Industrial Informatics 7(3):381-388

29. Pearce J (2009) Expanding photovoltaic penetration with residential distributed generation from hybrid solar photovoltaic and combined heat and power systems. Energy 34(11):1947-1954

30. Tasdighi M, Ghasemi H, Rahimi-Kian A (2014) Residential Microgrid Scheduling Based on Smart Meters Data and Temperature Dependent Thermal Load Modeling. IEEE Transactions on Smart Grid 5(1):349-357

31. US-DoE (2006) Benefits of Demand Response in Electricity Markets and Recommendations for Achieving Them. A report to the United States Congress Pursuant to Section 1252 of the Energy Policy Act of 2005

32. Widén J (2014) Improved photovoltaic self-consumption with appliance scheduling in 200 single-family buildings. Appl Energy 126:199-212

33. Yang HT, Huang CM, Huang CL (1996) Identification of ARMAX model for short term load forecasting: an evolutionary programming approach. IEEE Trans Power Systems 11(1):403408 